\title{
A COOPERAÇÃO MULTIPROFISSIONAL NO PLANEJAMENTO PEDAGÓGICO DA EDUCAÇÃO EM TEMPO INTEGRAL: Um estudo descritivo de quatro escolas municipais de Lagarto-SE
}

\author{
Heike Schmitzl \\ Aila Santana de Amorim Silva² \\ Themyres Gabriele Santos Almeida ${ }^{3}$ \\ Ilse Kamski 4
}

\section{RESUMO}

A extensão da jornada escolar, que visa ampliar oportunidades educativ as e que prevê para tal fim a inserção de atores extraclasse, implica desafios no planejamento pedagógico escolar, particularmente quando se exige a articulação entre o currículo escolar e a oferta extraclasse. O planejamento se reflete na proposta pedagógica a ser, conforme legislação, elaborada com participação dos professores. Parece plausív el envolver nas escolas em tempo integral também os demais atores env olvidos nos processos escolares de ensino. Por meio de um estudo de caso descritivo em quatro escolas municipais de Lagarto/Sergipe, buscou-se compreender se e como cooperam os atores extraclasse com os atores escolares. As respostas das coordenadoras pedagógicas, professores e monitores revelaram dificuldades para uma cooperação multiprofissional principalmente entre professores e monitores, mas foi confirmada uma cooperação no planejamento e na operacionalização das atividades entre monitores e coordenadoras da oferta extraclasse e entre estas e a coordenação escolar. Em diversos aspectos, os resultados desse estudo descritivo são semelhantes às revelações de um estudo alemão, de natureza quantitativa, a que se recorreu aqui para a discussão.

Palavras-chave: Cooperação Multiprofissional. Gestão educacional. Planejamento pedagógico.

\footnotetext{
1 Doutora em Educação. Professora do Departamento de Educação e do Programa de Pósgraduação em Educação da Universidade Federal de Sergipe (UFS), São Cristóvão/SE. Líder do Grupo de Pesquisa em Avaliação, Política, Gestão e Organização da Educação APOGEU. ORCID iD: http://orcid.org/0000-0002-5291-1354. E-mail:hs.contato.ufs@gmail.com

2 Mestre em Educação pela Universidade Federal de Sergipe (UFS). Membro do Grupo de Pesquisa em Avaliação, Política, Gestão e Organização da Educação - APOGEU. ORCID iD: http://orcid.org/0000-0002-6842-9415. E-mail: ailaamorim@hotmail.com

3 Mestranda da pós-graduação em Educação da Universidade Federal de Sergipe (UFS), São Cristóvão/SE e bolsista CNPq. Líder do Grupo de Pesquisa em Avaliação, Política, Gestão e Organização da Educação - APOGEU. ORCID iD: http://orcid.org/0000-0001-52783965. E-mail: themiresgabriele@gmail.com

4 Pesquisadora no Institut für Schulentwicklungsforschung (Technische Universität Dortmund (Alemanha). ORCID iD: https://orcid.org/0000-0003-3476-7106. E-mail: ilse.kamski@tudortmund.de
} 


\section{A MULTIPROFESSIONAL COOPERATION IN PEDAGOGICAL PLANNING OF FULL- TIME EDUCATION: a descriptive study of four municipal schools of Lagarto-SE}

\section{ABSTRACT}

The extension of the school day that provides for expanded education opportunities and that for this purpose includes the insertion of extracurricular actors means challenges for pedagogical school planning, especially when the school curriculum and the extracurricular offer have to be linked to each other. The planning is reflected in the pedagogical proposal that, according to legislation, has to be elaborated with the teachers' participation. It seems to be plausible to include all other actors that are inv olved in the school teaching processes in full-time schools. By a descriptive case study in four municipal schools in Lagarto / Sergipe, it was sought to understand if and how the extracurricular actors cooperate with the school actors. The responses of the pedagogical coordinators, teachers and workshop instructors revealed difficulties in the multiprofessional cooperation, mainly between teachers and workshop instructors, but the cooperation in the planning and operationalization of the activities between the workshop instructors and the coordinators of the extra class offer and between these coordinatores and the school coordination was confirmed. In several aspects, the results of this descriptive study are similar to the findings of a quantitative German study that has been used in this paper for discussion.

Keywords: Multiprofessional Cooperation. Education management. Pedagogical planning.

\section{LA COOPERACIÓN MULTIPROFESIONAL EN LA PLANIFICACIÓN PEDAGÓGICA DE LA EDUCACIÓN EN TIEMPO INTEGRAL: un estudio descriptivo de cuatro escuelas municipales de Lagarto-SE}

\section{RESUMEN}

La ampliación de la jornada escolar que busca aumentar las oportunidades educativas, y que predice la inserción de actores extraescolares, coloca desafíos a la planificación pedagógica escolar, particularmente cuando se exige la articulación entre el currículo escolar y la oferta extraescolar. La planificación se refleja en la propuesta pedagógica a ser, conforme con la legislación, elaborada con la participación de los profesores. Parece plausible envolver en las escuelas a tiempo completo los demás actores involucrados en los procesos escolares de enseñanza. Por medio de un estudio de caso descriptivo, en cuatro escuelas municipales de Lagarto / Sergipe, se buscó comprender si y cómo cooperan los actores extraescolares con los actores escolares. Las respuestas de los coordinadores pedagógicos, los profesores y los monitores rev elaron dificultades en la cooperación multiprofesional, principalmente entre profesores y monitores, pero se confirmó una cooperación en la planificación y en la operacionalización de las actividades entre monitores y coordinadores de la oferta extraclase y entre ellos y la coordinación escolar. En div ersos aspectos los resultados de este estudio descriptivo son similares a las revelaciones de un estudio alemán, de naturaleza cuantitativa, que también se utilizó para delinear la discusión. 
Palabras clave: Cooperación Multiprofesional. Gestión educativa. Planificación pedagógica.

\section{INTRODUÇÃO}

A concepção da educação em tempo integral no Ensino Fundamental, induzida em âmbito nacional, no ano de 2007, pela política federal do Programa Mais Educação (PME), instituída pela Portaria Interministerial $n^{\circ} 17$ de 24 de abril de 2007 (BRASIL, 2007) e regulamentada pelo Decreto $n^{\circ} 7.083 / 2010$ (BRASIL, 2010), previu uma articulação da proposta pedagógica e extraclasse da escola ofertada. A primeira no turno regular e a segunda no contraturno. A oferta extraclasse é composta por um acompanhamento pedagógico obrigatório e oficinas temáticas, atribuídas a diferentes áreas de conhecimentos. Após a reformulação da política, o Programa Novo Mais Educação (PNME), implementado em 2016, por meio da Portaria $n^{\circ} 1.144$, de 10 de outubro de 2016, continua apostando no modelo adicional, ou seja, na combinação do turno regular e turno oposto, e também sustenta que deve ocorrer a integração com as atividades realizadas no turno regular. 5

Para a articulação e coordenação entre ensino regular e oferta extraclasse, foi, conforme PME, implementado um cargo específico na escola - o(a) chamado(a) professor(a) comunitário(a)- que é, atualmente, no PNME, chamado de articulador. As competências de ambos pouco se distinguem. Especificamente, atribui-se a essa função a integração das atividades socioeducativas do contraturno com as atividades do ensino regular em um planejamento pedagógico. Cabe também a promoção de um diálogo entre atores do turno regular e das pessoas que ministram as atividades extraclasses (BRASIL, 2009; BRASIL, 2016).

As pessoas que ministram a oficina de acompanhamento pedagógico e as atividades ligadas aos macrocampos não são necessariamente professores da escola. Na implementação do PME, no qual são chamados

\footnotetext{
5 No entanto, o Programa Novo Mais Educação (PNME) dá, à escola, a opção de implementar uma educação em tempo integral ( 15 horas semanais além do ensino regular) ou ofertar uma jornada estendida (por 5 horas semanais além do ensino regular).
} 
de monitores, recomendou-se que os professores da escola não assumissem as oficinas de atividade extraclasse quando isso significasse ressarcimento de despesas com recurso do Fundo Nacional de Desenvolvimento da Educação (FNDE). No PNME, essa função se diferencia entre mediadores (responsáveis pelo acompanhamento pedagógico em alfabetização e letramento em português e matemática) e facilitadores (responsáveis pelas oficinas de outras áreas).

Uma extensão da jornada escolar para uma educação em tempo integral com essa proposta, ou seja, com a diversificação da oferta extraclasse e a inserção de novos atores (extraclasse) de diferentes graus de formação e, oriundas de diversas áreas de conhecimento, sem ter necessariamente conhecimento da área educacional, causa desafios para a gestão da instituição de ensino. Isso porque é caracterizada pelo empenho de profissionais com conhecimento especializado e competências técnicas na área educacional (RÖBKEN, 2008). Por isso, objetivamos aqui descrever os obstáculos que a escola brasileira, participante do PME, enfrentou a respeito da coordenação das ações pedagógicas, articulando o ensino regular dos professores da escola e a oferta extraclasse ministradas por atores extraclasse, ou seja, objetivamos descrever os desafios para fortalecer a cooperação multiprofissional. Esperamos, com esse conhecimento, contribuir na consolidação da educação em tempo integral no Brasil.

Estimulou-nos para tal objetivo de pesquisa, o Estudo sobre o Desenvolvimento de Escolas em Tempo Integral (Original: Studie zur Entwicklung von Ganztagsschulen - StEG) 6 que, entre outros focos, investigou

\footnotetext{
6 O estudo, encomendado pelo Ministério de Educação com a finalidade de monitorar os efeitos da política Programa de Investimento Futuro Educação e Cuidado (Original: "Zukunft Bildung und Betreuung" - IZBB), iniciou em 2005 com mais de 300 escolas em tempo integral. Desde então se acompanha cientificamente em um estudo transversal e longitudinal, o desenvolvimento organizacional das escolas com o objetivo de descrever (as condições d)o trabalho em escolas em tempo integral para poder estimular um trabalho escolar voltado na base de evidências científicas e dar um devido apoio por meio de políticas educacionais. Os levantamentos de dados quantitativos, também chamadas de ondas, ocorrem cada dois anos desde 2005. Mais informações se encontram no homepage do estudo: https://www.projekt-steg.de/
} 
a cooperação multiprofissional de atores escolares e extraclasse em escolas alemãs ${ }^{7}$. Os resultados dessa pesquisa alemã despertaram a nossa curiosidade no sentido de observar se eles parecem com os resultados obtidos de quatro escolas em tempo integral de Lagarto-Sergipe.

Justifica-se esse olhar devido ao fato de que a concepção da educação em tempo integral no Brasil apresenta semelhanças com a da Alemanha (SCHMITZ, ROLLETT, SILVA, 2017). Além disso, a articulação entre ensino em sala de aula e atividades extraclasse faz parte da definição legal de uma escola em tempo integral na Alemanha (KMK, 2015). Lá também se estimulou a inserção de pessoas extraescolares na oferta extraclasse, porque buscou integrar profissionais de diversas áreas de conhecimento, envolvendo-se nela não apenas pessoas com formação pedagógica, mas também pessoas sem (ou com apenas incompleta) formação pedagógica ou educacional. O impulso para essa ampliação e diversificação da jornada escolar foram os resultados abaixo do esperado dos seus alunos na primeira edição do Programa Internacional de Avaliação de Estudantes (Original: Programme for International Student Assessment - PISA), em 2000. Entre outras reformas, atribui-se à implementação da educação em tempo integral a expectativa de promover habilidades dos alunos, referente a disciplinas escolares e interdisciplinares, um aumento da igualdade de oportunidades de aprendizagem, um cuidado/atendimento mais individualizado e uma maior integração sociocultural.

\footnotetext{
7 Chamamos aqui ator/pessoal extraclasse, o additional staff ou seja, as pessoas que participam na realização de ações pedagógicas sem ser professores da escola. No contexto do Programa Mais Educação são os professores comunitários e os monitores. No contexto do Programa Novo Mais Educação, são os articuladores, mediadores e facilitatores. No PNME recomenda-se como perfil para mediadores do acompanhamento pedagógicos de alunos nas series iniciais do Ensino Fundamental professores (com pósgraduação em educação, licenciados em Pedagogia), professores com ensino médio na modalidade normal, como também estudantes universitários (do curso de Licenciatura em Pedagogia) e educadores populares que concluíram o ensino médio, que demonstrem experiência com educação integral na área de alfabetização (BRASIL, 2018). Para os alunos das series finais do Ensino Fundamental se especifica 0 perfil desejado para 0 acompanhamento pedagógico em língua portuguesa e para matemática (BRASIL, 2018). No que diz respeito aos facilitadores, o novo programa estabelece que sejam pessoas com experiência na área que vão atuar (BRASIL, 2018).
} 
Para alcançar essas expectativas socioeducacionais atribuídas à educação em tempo integral, concordamos com Milheiro ao suspeitar que a "[...] cooperação docente será uma estratégia que propõe tornar os professores mais eficientes na sua tarefa e que irá trazer grandes benefícios nas aprendizagens das crianças" (MILHEIRO, 2013, p. 45), e também aplicamos essa suposição à cooperação multiprofissional.

Por causa disso, torna-se preciso investigar melhores condições para que essa cooperação multiprofissional possa ocorrer. Nesse sentido, perguntamos: Como o pessoal extraclasse é incluído no planejamento e na realização da proposta pedagógica da escola? Aconteceu cooperação entre o pessoal extraclasse e o corpo docente? Quais as condições desfavoráveis e favoráveis para a cooperação multiprofissional na percepção das pessoas que se envolvem no processo de ensino e aprendizagem sem ser professor da rede?

As pergunt as se formularam, como anteriormente mencionado, diante alguns resultados do estudo empírico alemão, StEG, que chamaram a nossa atenção. Constatou-se no contexto da educação em tempo integral alemão que o nível de cooperação era, muitas vezes, baixo, tanto no que diz respeito à qualidade como à intensidade (DIECKMANN; HÖHMANN; TILLMANN, 2007). As investigações científicas revelaram também condições desfavoráveis que geram a falta ou a dificuldade de cooperação. Kamski e Schnetzer (2005) apontam a falta de apreciação mútua. Professores, por exemplo, consideram o pessoal extraclasse como apoio ou ajudante ao seu próprio trabalho, inclusive por causa da demarcação funcional na escola devido à diferente formação técnica profissional; ou entendem a atuação do pessoal extraclasse como alternativa ao trabalho do professor em vez de enxergá-la como complementação articulada a esse. Os autores também revelam que as escolas ainda demandam uma estrutura comunicacional eficaz e eficiente, tanto para facilitar uma articulação pedagógica como também servir para uma cultura de respeito mútuo.

Esses resultados nos fizeram perguntar aos participantes da pesquisa se há cooperação no planejamento e na execução da oferta pedagógica. 
Para verificar se houve uma institucionalização dessa cooperação foi perguntado também sobre a intensidade (frequência), espaços e tempos institucionalizados para cooperar e os motivos da (não) cooperação (partilhar informações; planejar; executar).

Os dados foram levantados no contexto da pesquisa empírica $O$ desenvolvimento organizacional da escola em tempo integral8. Aqui focalizamos na apresentação daqueles dados que nos permitem os insights específicos sobre a cooperação entre pessoas que ministram as atividades extraclasse e a coordenação delas. Um levantamento das produções acadêmicas e publicações científicas, realizado em 20 de fevereiro de 2018, com palavras-chave "Educação Integral" e "Mais Educação", na Biblioteca Digital Brasileira de Teses e Dissertações (BDTD), mostrou que nenhum dos trabalhos científicos encontrados nessas plataformas trata especificamente da cooperação entre professor e pessoal extraclasse (do Programa Mais Educação ou Programa Novo Mais Educação). Isso torna a descrição de experiências empíricas sobre a cooperação multiprofissional ou empecilhos para tal ainda mais pertinente.

\section{COOPERAÇÃO MULTIPROFISSIONAL EM ÂMBITO ESCOLAR}

O conceito de cooperação, aplicado na nossa pesquisa, é deduzido da concepção de Johnson e Johnson (1989 apud SILVA, 2002, p.11) que a compreendem como "um processo interactivo [sic] que proporciona às pessoas, com diversos conhecimentos, soluções criativas para muitos problemas previamente definidos, sendo que a sua base é a interdependência social positiva" e a de Palmiere e Branco (2004) que a definem como "[...] ações ou atividades consideradas como socialmente positivas, visando atender às necessidades e ao bem estar de outras pessoas" (PALMIERE; BRANCO, 2004, p. 190). Palmiere e Branco (2004) enfatizam que vivenciar situações cooperativas favorece a continuação de comportamentos socialmente positivos, por exemplo, atitudes de suporte e

\footnotetext{
8 Pesquisa registrada sob registro PVD3659-2015, no sistema integrador da Universidade Federal de Sergipe, que conta com dois bolsistas (PIBIC/Copes e PIBIC, vol.), realizada entre 2015 e 2016.
}

Revista Exitus, Santarém/PA, Vol. 9, №3, p. 339 - 364, JUL/SET 2019. 
apoio mútuo, reconhecimento do valor do trabalho do outro, diálogos e acompanhamento dos profissionais principiantes por profissionais experientes. Um ambiente marcado por esses comportamentos pró-sociais, como os autores os chamam, é um solo fértil para fortalecer o trabalho em equipe. E, a partilha de informações, experiências, crenças, valores, objetivos, são ingredientes chaves da cooperação. Já ao contrário, os ambientes competitivos podem levar, conforme os autores, à hostilidade e agressão.

Incluímos na nossa concepção o aspecto do agir consciente e planejado segundo as funções que Pugach e Johnson associam à cooperação. São elas:

(i) apoiar ou suportar os colegas que enfrentam dificuldades; (ii) facilitar ou promover o desenvolvimento profissional dos colegas; (iii) informar e partilhar experiências; (iv) prescrever um conjunto de medidas a ser implementadas por outros colegas, que beneficiam de uma ajuda complementar (PUGACH; JOHNSON, 1995, p. 172-174 apud MILHEIRO, 2013, p. 25; grifo nosso)

Dessa forma, entendemos, que cooperação é uma ação em conjunto por pessoas que se ajudam mutuamente de forma voluntária, em busca de um planejamento de objetivos e sua realização em prol do atendimento das necessidades de cada um e do bem-estar coletivo. Os objetivos não precisam ser necessariamente altruístas. A motivação de cooperação não apenas sugere por querer o bem-estar do outro; também podem surgir do interesse próprio e da expectativa de ganhos individuais. Conforme Agostinho (2003), referindo-se à Teoria de Cooperação de Axelrod, aponta "que a cooperação pode emergir, sem a presença de autoridade central ou de forças coercitivas, a partir de indivíduos que buscam seu próprio benefício." (AGOSTINHO, 2003, p. 10). Pois, assim continua o autor, o

[...] incentivo para cooperar está na percepção de que é possível a obtenção de ganhos através da ajuda mútua, ou melhor, que o desempenho de cada um pode ser superior ao que seria possível caso não contasse com a cooperação dos demais (AGOSTINHO, 2003, p. 10). 
A compreensão aqui aplicada corresponde, de certa forma, com a definição aplicada em pesquisas alemãs. Bergmann e Rollet† (2008), com referência ao conceito da psicologia organizacional, incorporam na sua definição o aspecto da referência ao outro e à reciprocidade, aos objetivos a serem alcançados coletivamente, à intencionalidade, à comunicação e à confiança. Na sua definição também incluem o fato de que a cooperação pressupõe certa autonomia das pessoas.

Concordamos com Fussangel e Gräsel (2010) que consideram problemático falar "da" cooperação já que ela pode se representar de diversas maneiras. Referindo-se a pesquisas anteriores, as autoras falam de três formas: partilha, divisão de trabalho e co-construção. A definição aplicada em nossa pesquisa abrange também essas três formas. O processo de partilha objetiva que todos envolvidos possam ter o mesmo grau de informações. A divisão de trabalho focaliza na maior eficiência do cumprimento de tarefas. A co-construção se refere à cooperação no enfrentamento de desafios didáticos e à elaboração de propostas de atividades pedagógicas.

No modelo de Gräsel, a co-construção constitui a mais elevada forma de cooperação. As autoras alertam que para um fortalecimento de cooperação precisa-se de objetivos claros e uma atribuição clara de funções ou tarefas parciais de cada um em prol da melhor orientação de todos os envolvidos. Kamski (2011) ainda aponta a utilidade de diferenciar a cooperação intraescolar e extraclasse. A última abrange a cooperação de atores escolares com parceiros da escola ou escolas parceiras, redes escolares, com patrocinadores. Na cooperação dentro da escola se pode diferenciar entre a cooperação com os alunos, a cooperação com os pais e responsáveis e a cooperação entre o pessoal do ensino. Essa última é o foco da nossa pesquisa.

\section{ACESSO E DESCRIÇÃO DO UNIVERSO DA PESQUISA EMPÍRICA E TÉCNICAS APLICADAS}

Revista Exitus, Santarém/PA, Vol. 9, N 3, p. 339 - 364, JUL/SET 2019. 
Escolhemos como local da pesquisa o município de Lagarto, situado na região Centro-Sul do Estado de Sergipe. Foi por meio do Programa Mais Educação que a educação em tempo integral chegou às escolas da rede pública desse município, em meados de 2009.

A nossa pesquisa descritiva foi desenvolvida em duas escolas localizadas na zona urbana e duas na zona rural. As escolas são aqui denominadas, para manter o sigilo, Escola A, Escola B, Escola C e Escola D. Em total participaram 24 pessoas. Seis participantes desta pesquisa atuam na Escola A, cinco na Escola B, oito na Escola C e cinco na Escola D. Duas pessoas eram responsáveis pela gestão escolar, quatro pela coordenação pedagógica, quatro são professores comunitários e quatorze eram monitores.

No que diz respeito ao perfil dos participantes, duas professoras comunitárias eram formadas em pedagogia e duas eram ainda estudantes da graduação. Apenas a professora comunitária da Escola C tinha experiência em coordenação e em funções administrativas da secretaria antes de assumir a coordenação do PME na escola. Para essa função, três informaram que foram convidadas pelos gestores e uma foi indicada pela Secretaria Municipal de Educação (SEMED). Três dos monitores tinham completado seu Curso de Graduação, nove monitores estavam em formação a nível superior. Estudaram em diversos campos de conhecimento: Música, Biologia, Educação Física, Letras e Pedagogia. Constatou-se que eles atuaram em oficinas temáticas coerentes com seus cursos de graduação. Um monitor ainda era aluno do Ensino Médio, atuante na oficina de capoeira. Dessa forma, cumpriam o perfil recomendado no Manual Operacional do PME (BRASIL, 2014). No entanto, nenhum deles foi bolsista do Programa Institucional de Bolsa de Iniciação à Docência (PIBID), como também desejado explicitamente no documento. Oito dos quatorze monitores, não moravam na comunidade, na qual a escola está inserida.

A pesquisa ocorreu com o consentimento da coordenação municipal do Programa Mais Educação e após todos os participantes terem assinado um termo de consentimento livre e esclarecido. As concepções e opiniões 
dos monitores foram levantadas por meio de um questionário, aplicado em um momento coletivo e as dos coordenadores por meio de entrevista. As entrevistas foram conduzidas, em cada escola, ainda no mesmo dia após ter aplicado o questionário com os monitores.

\section{RESULTADOS}

Perguntamos aos gestores participantes dessa pesquisa se há envolvimento da coordenação da oferta extraclasse no planejamento pedagógico da escola. Eles nos disseram, nas suas devidas entrevistas, que as professoras comunitárias são informadas sobre questões relacionadas à gestão escolar da escola, como por exemplo, sobre a organização/desenvolvimento das pessoas, a configuração do espaço, organização do tempo, almoço e lanches, abertura institucional da escola e a participação nos processos de tomada de decisão. Três das quatro professoras comunitárias confirmaram isso, nas suas entrevistas.

Especificamente no que diz respeito ao planejamento pedagógico coletivo do ano letivo, foi confirmado tanto na Escola $A$, como também na Escola $B$ e $C$, que as professoras comunitárias, foram, juntamente com os professores do ensino regular, convidadas para participar da semana pedagógica, que ocorreu no início do ano letivo. Na Escola $D$ a coordenadora pedagógica informou não ter convidado à professora comunitária "porque ainda não estava determinado quando iria começar o Mais Educação. " (Coordenadora pedagógica da Escola D).

Na Escola A, além da professora comunitária, também dois monitores participaram da Semana Pedagógica no início do ano letivo com os professores. No que diz respeito ao envolvimento dos monitores no planejamento pedagógico da escola, perguntamos aos gestores, coordenadoras e professoras comunitárias se são previstos horários/tempos fixos para que os monitores possam tirar dúvidas ou trocar informações com eles pessoalmente. Constatamos que em nenhuma escola há a preservação de um horário ou tempo fixo, ou seja, não há um horário determinado na grade dos profissionais dedicado a trabalhos cooperativos. Para isso, como 
revelou, por exemplo, a resposta da coordenadora pedagógica da Escola D, "se aproveita os 15 minutos de intervalo dos monitores" (Coordenadora pedagógica da Escola D) ou as "horas vagas no horário de almoço (dois monitores almoçam na escola)", conforme mencionou a professora comunitária da Escola B. Já na Escola C, a professora comunitária disse que "só se tiver uma reunião no sábado, aí eles podem participar" (Professora comunitária da Escola C), de acordo com ela, isso acontece porque os monitores trabalham em outra escola.

Os monitores da Escola B, Escola C e Escola D também apontaram que as reuniões não são em horários regulares. Os monitores da Escola A confirmam que existem reuniões pedagógicas entre monitores e a professora comunitária. Quanto aos horários das reuniões pedagógicas na Escola A, um monitor falou que elas sempre ocorrem no turno da manhã, mas não especificou em que horário. Seu colega respondeu que as reuniões acontecem "informalmente, sempre que necessário, e o tempo que estiver disponível." (Monitor 3 da Escola A).

Todos os monitores das quatro escolas informaram que não existe um horário fixo de atendimento pela professora comunitária, mas que isso não significa que eles não estão sendo acompanhados e orientados. Perguntados quando foi à última vez que eles receberam orientação pela professora comunitária, revelou-se que houve orientações recentes.

Na maioria, os encontros são usados para uma troca de experiências e informações. Onze monitores aproveitaram esses momentos para fazer, eles próprios, sugestões para a professora comunitária em prol da melhoria da oferta das atividades extraclasse. Um monitor da Escola A, dois da Escola B, três da Escola $D$ e todos da Escola $C$, confirmaram ter comunicado também sugestões para melhorar a articulação da sua oficina com os saberes locais. Também queríamos saber se havia ajuda mútua entre monitores. Onze dos quatorze monitores confirmaram que outros colegas monitores já recorreram a eles para pedir ajuda e que eles ajudaram. Os outros três disseram que nenhum colega havia solicitado ajuda. 
As informações fornecidas fazem suspeitar que ainda não foi estabelecido um ambiente cooperativo estável. Para tal, encontros regulares ou espaços reservados para encontros de monitores poderiam contribuir para uma comunicação mais contínua sobre as experiências. E um horário fixo para cooperação pareceu ser do interesse dos monitores. Na opinião dos monitores das quatro escolas valeria a pena investir tempo em uma cooperação.

Doze monitores confirmaram que gostariam de desenvolver um trabalho coletivo com um ou mais professores da escola na qual executam suas oficinas. Dois responderam que não gostariam. E perguntado aos monitores se, na opinião deles, o monitor deveria tirar dúvidas diretamente com professores da escola, nove monitores responderam que sim e cinco monitores (dois da Escola A, três da Escola C) responderam não ser necessário tirar dúvidas com professores. De acordo com um dos monitores da Escola C, os professores "deveriam pedir ajuda ao monitor".

Cabe frisar que na Escola A, o gestor e a coordenadora pedagógica, como também a professora comunitária, confirmaram que é possivel tirar dúvidas com os professores. Na Escola C, a coordenadora e gestora apontam que os monitores devem procurar os professores, mas a professora comunitária não concorda com isso. Na Escola D a coordenadora pedagógica não vê necessidade de o monitor tirar dúvidas diretamente com o professor, já que eles têm acesso ao planejamento anual dos professores, mas na opinião da professora comunitária o monitor deveria tirar dúvida com os professores.

Aqui percebemos que, o contexto organizacional não reuni as pessoas que estão diretamente atuando em sala de aula (professores) e oficinas (monitores) para o planejamento, elaborado em conjunto, do ensino regular e da oferta extracurricular, apontado como fator favorável para alcançar os objetivos educacionais coletivos da educação em tempo integral. O acesso ao planejamento anual dos professores pela professora comunitária não significa um planejamento coletivo no qual a coordenadora das atividades extraclasse e os monitores que as ministram participaram ativamente. 
Em nenhuma das quatro escolas há um tempo/horário previsto/planejado para que os monitores possam cooperar diretamente com os professores do ensino regular. Na Escola C a gestora disse que ocorrem encontros, mas a professora comunitária, a coordenadora pedagógica e os monitores não confirmaram isso. Conforme as professoras comunitárias da Escola A e B há encontros entre monitores e professores de área afins das suas oficinas, contudo, isso tampouco não foi confirmado pelos próprios monitores. Todos os monitores dessas instituições informaram que não há esse tipo de encontros. Já na Escola D a professora comunitária disse não ter organizado encontros "porque os professores trabalham em outro turno". (Professora comunitária da Escola D). Também o gestor da Escola A apontou que a dificuldade dessa cooperação entre professor e monitor, é devido à falta de tempo do professor e porque "os encontros que acontecem fora do horário, eles não vêm" (Gestor da Escola A). A coordenadora pedagógica da Escola A concorda com o argumento do gestor no que diz respeito à falta de tempo e acrescenta ainda a infraestrutura limitada. A coordenadora pedagógica da Escola B também apontou a falta de tempo/horário dos professores para cooperar, mas disse que, quando acontecem projetos, esses sim, são planejados juntos. Mas não é só no contexto de projetos específicos que uma troca de experiências se tornaria pertinente, pois foi perguntado aos monitores se já sentiram dificuldade em ministrar oficinas. Cinco monitores informaram que não, mas quatro monitores confirmarm ter dificuldades e cinco disseram que às vezes sentem dificuldades.

As respostas dos participantes fazem suspeitar que não há uma cooperação entre monitores e professores por falta de disponibilidade dos próprios professores. Há "falta de credibilidade (confiança) ao PME por parte dos professores", relata a professora comunitária da Escola B. Também informa que os "professores não enxergam o PME como projeto da escola, não dialogam, não deram apoio ao programa". As professoras comunitárias da Escola A, Escola C e Escola D observaram que existem ainda alguns professores que mostram resistência. Tanto que a professora comunitária da 
Escola A ainda especifica que alguns professores creem que os monitores que ainda não são formados não podem realizar as oficinas. A coordenadora do programa na Escola $C$ apontou que não há cooperação por "falta de disposição dos professores".

Os obstáculos relatados correspondem com a percepção dos monitores. Para realizar uma cooperação com os professores da escola há falta de tempo, interesse e disponibilidade do professor. Foi destacado que os professores "não estão abertos a diálogos" (Monitor 1 da Escola A). Conforme o monitor 2 da Escola A, "os professores desta escola [...] tem o Mais Educação como se fosse algo sem benefício sendo que não respeita nosso trabalho, dizem que não somos capazes de ministrar as aulas". O monitor também frisou que "os monitores não são vistos como 'educadores' como eles [professores]" (Monitor 3 da Escola A).

A opinião dos monitores da Escola B e D são semelhantes aos dos colegas da Escola A. Eles identificam que a ausência de encontros entre os atores extraclasse do PME e professores dificulta a cooperação. O monitor 1 da Escola B indicou que "falta encontros para cooperação conjunta." (Monitor 1 da Ecola B). Outro ponto levantado é que os professores são "desmotivados, portanto, não se envolvem a nada relacionado ao Mais Educação." (Monitor 2 da Escola B). Essa percepção sobre as dificuldades encontradas foi predominante entre todos os monitores.

Uns dos possíveis motivos são os "horários, na maioria das vezes não são iguais uns com os outros." (Monitor 1 da Escola D). Isso também foi frisado por outro monitor, apontando que falta "tempo disponível de ambas as partes" (Monitor 2 da Escola D). Na Escola C foram levantadas, além dos obstáculos já mencionados, ainda outras questões pelos monitores. Foi explicitado que existe "uma espécie de separação", isto é, "cada um faz o seu trabalho" (Monitor 2 da Escola C). Conforme os monitores, existem ruídos na comunicação entre eles e a gestão, pois "algumas pessoas da gestão têm preconceito com os monitores" (Monitor 3 da Escola C). Apontaram também a "falta de organização e interesse dos coordenadores e diretores 
das escolas" (Monitor 3 da Escola C) e o "orgulho do lado dos professores por ser superior aos monitores" (Monitor 5 da Escola C).

Percebemos aqui que o papel do monitor não foi compartilhado de forma clara com a comunidade escolar, mas pudemos verificar que os gestores e as coordenadoras conhecem a função do monitor, como previsto no programa. Na Escola A, o gestor percebe os monitores como "[...] colaboradores que estão contribuindo para a comunidade" e a professora comunitária como "ajuda e colaboração [...] para o professor". Para a coordenadora pedagógica da Escola B, os monitores ajudam a "melhorar a qualidade do aprendizado" e conforme a professora comunitária, os monitores contribuíam para o "esclarecimento de conteúdos" e na "conversa sobre comportamento dos alunos". Na Escola D, a coordenadora pedagógica enxerga na presença dos monitores uma contribuição "para engajar as atividades, somar conhecimentos, ajudar aos professores, por exemplo, em tarefas de casa". Segundo a professora comunitária da mesma escola "tem que ter esse elo, é continuação daquilo que os alunos viram pelo ensino regular" (Professor comunitário da Escola D). Na Escola C, a gestora indica que os monitores estão na escola para "melhoria do nosso ensino" e por isso eles devem "conquistar os pais através do nosso aluno" (Gestora da Escola C). Do ponto de vista da coordenadora pedagógica dessa escola é "uma oportunidade de um auxiliar o outro".

Mesmo a gestão e a coordenação pedagógica, tanto do ensino regular como da oferta extraclasse, tendo essa concepção do papel do monitor na educação em tempo integral, parece que essa não foi socializada suficientemente com o corpo docente. Não há, assim, conforme indicam as falas dos monitores, uma concepção compartilhada da sua função na educação em tempo integral. Desta forma, se autoboicota, a nosso ver, que "o Mais Educação vem somar para melhorar a aprendizagem do aluno", expectativa pronunciada pela coordenadora pedagógica da Escola A.

\section{DISCUSSÃO DOS RESULTADOS}

Revista Exitus, Santarém/PA, Vol. 9, № 3, p. 339 - 364, JUL/SET 2019. 
Os participantes desta pesquisa confirmaram a cooperação entre a coordenação da oferta extraclasse (professora comunitária) e a gestão escolar e coordenação pedagógica, como também entre a professora comunitária e as pessoas que ministram as atividades extraclasse (monitoras). No entanto, não há cooperação entre o pessoal da oferta extraclasse e os professores do ensino regular. É interessante que a pesquisa alemã StEG chegou, no levantamento inicial, em 2005, a um resultado semelhante. Na média, os professores raramente cooperam, ou seja, menos do que trissemestral, considerado suboptimal (DIECKMANN; HÖHMANN; TILLMANN, 2007).

A falta de infraestrutura é um obstáculo que inibe ou dificulta a cooperação entre o pessoal do ensino regular e o da oferta extraclasse. Concordamos aqui com as constatações das participantes desta pesquisa no que diz respeito à falta de infraestrutura favorável para a cooperação multiprofissional. Nas visitas às quatro escolas observamos as limitações descritas pelos entrevistados, no entanto, também percebemos espaços que poderiam ser, pelo menos provisoriamente, melhor aproveitados após a adaptação do local. Por exemplo, as escolas têm espaços externos (pátios) que não são utilizados devido à falta de proteção do sol para os quais se poderiam achar soluções de coberturas por telas de tecido ou plantas. Espaços como esses já podem servir para criar rituais com horários dedicados a encontros entre os monitores (de sala de reunião até o cantinho de café para intervalo), abrindo oportunidades de conversas nas quais se poderia perceber um possível ganho de ajuda mútua ou para perceber que a cooperação poderá levar a um ganho, usando as palavras de Agostinho (2003, p. 10) que "pode ser superior ao que seria possível caso não contasse com a cooperação dos demais".

A falta de espaço é um obstáculo, e a falta de tempo foi outro obstáculo relatado. Ou falta tempo pelo lado dos professores que estão presentes na escola, na maioria, só por um turno, ou falta tempo por parte dos monitores que estão presentes na escola na hora da sua oficina. Os monitores não sentiram a disponibilidade por parte dos professores para a 
cooperação. Também nesse aspecto se apresenta semelhança com o resultado da pesquisa StEG. Na média, o pessoal extraclasse nas escolas em tempo integral, participantes do estudo, não sente que há uma forte integração deles com o corpo docente. Nas escolas primárias a situação é um pouco melhor do que nas demais escolas. Os dados alemães também fazem suspeitar que o modelo aditivo, ou seja, ensino regular em um turno e oferta extraclasse no turno oposto é uma condição menos favorável. Ocorre integração multiprofissional melhor nas escolas em tempo integral, que adotaram o modelo integrado que também permite a mesclagem entre ensino regular e oferta extraclasse.

Entre outros, há Estados da República Federativa da Alemanha que iniciaram uma reforma no sistema da liquidação do trabalho do professor, calculado anteriormente, conforme a obrigatoriedade de horas-aulas. Em Hessen, por exemplo, exige-se a presença semanal de 26 horas, reconhecendo além das aulas dadas, também os intervalos, outras atividades pedagógicas com os alunos e o tempo de planejamento cooperativo, exigindo, em total, 26 horas semanais de presença na escola (HOLTAPPELS, 1999). No Brasil, já se pratica a consideração do tempo de planejamento coletivo. A lei educacional prevê um "período reservado a estudos, planejamento e avaliação, incluído na carga de trabalho" (BRASIL, 1996, Art. 67, inciso v). E a Lei $n^{\circ} 11.738$, que regulamenta o Piso Salarial dos professores, diz que "na composição da jornada de trabalho, observar-se-á - limite de $2 / 3$ (dois terços) da carga horária para o desempenho das atividades de interação com os educandos." (BRASIL, 2008, art. $2^{\circ}$, parágrafo 4).

Além disso, tornou-se a incongruência entre o calendário escolar do ano letivo e o Programa Mais Educação, um empecilho para realizar um planejamento conjunto entre professores e monitores. Se tivesse um corpo de colaboradores voluntários estável, esse poderia participar no planejamento mesmo se suas atividades extraclasse iniciassem em tempo posterior ao início das aulas. 
Inquietou-nos a questão da implementação de um cargo específico de coordenação da oferta extraclasse. Implementar uma coordenação da oferta parece louvável, por institucionalizar o elo entre turno de ensino regular e turno oposto. A pessoa que assumiu esse cargo pode ser entendida como ponte que liga o trabalho do professor ao do monitor. No entanto, pode-se correr o risco de que se entenda mal a função dessa pessoa como a única responsável para um alinhamento entre planejamento individual já feito anteriormente pelo professor do ensino regular e o planejamento da oferta extraclasse do monitor, ou pior, que o monitor execute apenas um planejamento que o coordenador da oferta extraclasse elaborou após ter acesso ao planejamento dos professores.

Em outras palavras, inquietou-nos o perigo de que essa coordenação da oferta extraclasse levasse ao entendimento de que a cooperação direta entre monitor e professor seria desnecessária. Como vimos, o conceito de cooperação não se restringe apenas à partilha de informações, mas também à divisão de trabalho e, na forma mais desejada, na co-construção. Neste sentido, há de ter uma pessoa que proporcione as melhores condições para que ela aconteça. Isso implica a aproximação organizatória dos dois grupos (atores escolares e atores extraclasse), ou seja, organizar encontros, reuniões, registros/atas etc.) e a aproximação conceitual dos dois grupos, por exemplo, por meio de sensibilização mútua para as características profissionais de cada grupo e capacitações coletivas.

No levantamento inicial da pesquisa alemã StEG, em 2005, os gestores escolares informaram sobre a coordenação da oferta extraclasse por meio de um questionário. Na maioria $(84,1 \%)$ das 358 escolas participantes, a responsabilidade pela coordenação estava nas mãos dos próprios gestores escolares. Em 29,4\% das escolas, a função foi atribuída a um professor do corpo docente, e em 26,1\% para um grupo de gestão, em $21,9 \%$ em um órgão coletivo específico para a educação em tempo integral e em 21,1\% para uma pessoa específica (com formação pedagógica ou didática). Um olhar mais específico pode ainda diferenciar esse resultado: As escolas com menor (até 400 alunos) porte atribuem mais a coordenação ao gestor ou 
vice gestor da escola (94,0\%). Nas escolas de grande porte (mais de 700 alunos) também há o maior grupo cujo gestor assuma essa responsabilidade (62,8\%), mas também aumenta o percentual (chega a 54,0\%) daquelas que optaram por uma pessoa específica para coordenar a oferta extraclasse e a um conselho especial (32,0\%), ou seja, cresce o envolvimento direto daquelas pessoas na coordenação que ministram as atividades de ensino (DIECKMANN; HÖHMANN; TILLMANN, 2007).

A superação dos obstáculos acima descritos, que abre oportunidades para uma maior cooperação leva, conforme os achados de pesquisas, a efeitos positivos. A cooperação entre professores tem impacto positivo na redução de estresse profissional (HOLTAPPELS, 1999; FUSSANGEL et al., 2010), na implementação bem-sucedidas de inovações (HOLTAPPELS, 1999), na disponibilidade de abertura para inovações (BERGMANN; ROLLETT, 2008), na elaboração da concepção da educação em tempo integral e na proposta pedagógica da escola (HOLTAPPELS, 2007).

Suspeitamos que, no contexto das quatro escolas aqui analisadas, uma razão é a falta de comunicação institucional transparente e acessos a informações atualizadas. Alguns monitores acharam que podem/devem procurar diretamente os professores, outros não consideram isso possível ou oportuno. E nos Projetos Políticos Pedagógicos das escolas - ferramenta compreendida como norteadora das ações pedagógicas -, em apenas um consta o conceito de educação em tempo integral. Além disso, apenas um monitor confirmou conhecer o PPP da escola, isso revela que, além de o conceito da educação integral em tempo integral não estar inserido adequadamente na proposta pedagógica, também os monitores não estão comungando em sua prática cotidiana, os objetivos propostos pela instituição, já que não houve compartilhamento. Como os dados desta pesquisa mostraram, não parece suficiente criar condições para que monitores possam tirar dúvidas com os professores. Apenas a possibilidade em si não é suficiente para implementar uma cultura cooperativa. Há de ter, a nosso ver, um estímulo pelas coordenações pedagógicas da oferta 
extraclasse, para mover os atores (professores e monitores) a se aproximarem.

Diante disso, a indução ou o fortalecimento da cultura cooperativa na escola por meio da formação de pessoas e desenvolvimento institucional da gestão parece imprescindível. Devido à heterogeneidade do pessoal que atua em uma escola em tempo integral, como também a particularidade de cada Projeto Político Pedagógico com sua própria oferta extraclasse, a escola em tempo integral exige gestão escolar focalizada também no desenvolvimento dos recursos humanos. É preciso um conceito da utilização dos recursos humanos, especialmente se há descontinuidade do pessoal que atua na escola em tempo integral e diante da demanda de um "mix de governança" (concursado, seguindo a lógica do Estado, contratado, seguindo a lógica do mercado e voluntários, seguindo a lógica do Terceiro Setor) (KISSLER; HEIDEMANN, 2006).

Além disso, pesquisas (HORD, 1997; HOLTAPPELS, 2002; WEST; HIRST, 2003; GRÄSEL; FUSSANGEL, PRÖBSTEL, 2006 todos apud BERGMANN; ROLLETT, 2008), mostram que a cultura cooperativa e o espírito de equipe aumentam a disposição para inovações. O mesmo fenômeno foi verificado em escolas em tempo integral. Concordamos com Dieckmann, Höhmann e Tillmann (2007) que não haverá desenvolvimento organizacional da escola sem inovações. As autoras apontam que o clima inovador que faz parte do clima organizacional, é considerado um dos aspectos centrais para o sucesso de escolas em tempo integral eficazes. Diversos estudos (HOLTAPPELS et al., 2004; HOLTAPPELS, 1997, †odos apud DIECKMANN; HÖHMANN; TILLMANN, 2007) indicam uma correspondência entre grau do clima inovador e a cultura de aprendizagem diferenciada, espelhada na composição e configuração da oferta extraclasse. Bergmann e Rollett (2008) analisaram dados de 371 escolas, 8.837 professores e 1.759 pessoas, considerados extraescolares, que participaram do primeiro levantamento de estudo StEG em 2005. Sua análise descobre que professores que cooperam entre si não necessariamente também cooperam com pessoal extraescolar. Ou seja, não se pode deduzir que quando há cooperação entre professores, 
também haverá cooperação deles com o pessoal extraescolar. Mas a análise também mostra que as escolas nas quais os professores confirmam cooperar não só entre si, mas também com o pessoal extraclasse, apresentam uma disposição maior de inovação.

\section{CONSIDERAÇÕES FINAIS}

Mesmo cientes da limitação dos resultados de um estudo de caso descritivo, esperamos poder ter contribuído nas reflexões de como melhorar a eficácia da escola em tempo integral. A identificação de entraves e dificuldades da cooperação multiprofissional, observadas em quatro escolas, podem estimular um levantamento empírico de larga escala, para verificar se se trata de fenômenos apenas isolados ou se são fatos observados em um número significativo de escolas em tempo integral.

Caso não se trate apenas de um fenômeno isolado, o que faz suspeitar diante também dos resultados de pesquisas na Alemanha, vale investigar de forma mais aprofundada, como proporcionar melhores condições para a cooperação entre professores comunitários, monitores e professores. Também como melhor integrá-los em processos decisórios do planejamento educacional, para que todos estejam a par das decisões tomadas a respeito do desenvolvimento organizacional da escola, espelhado na elaboração e atualização constante do Projeto Político Pedagógico da escola.

Diante da discussão acima realizada parece plausível refletir sobre a alocação também de professores em jornada de tempo integral, a inserção de horários de cooperação nessa jornada e uma inserção/intensificação de conhecimento da gestão de pessoas na capacitação de gestores escolares. Sugerirmos para o nível municipal intensificar propostas de turno integral para os professores em escolas em tempo integral. A presença dos professores em tempo integral em uma instituição de ensino contribuiria para uma maior estabilidade, tendo em vista que há rotatividade, ou seja, flutuação em cada ano do programa, dos monitores que atuam no contraturno do ensino regular. Ao longo prazo poderia se configurar uma oferta mesclada de ensino regular e oferta extraclasse. 
E para os gestores ao nível organizatório/administrativo do Programa Novo Mais Educação recomendamos considerar a institucionalização na jornada escolar, um tempo disponibilizado para a cooperação entre professores e monitores, reconhecendo isso, inclusive, nos horários dos colaboradores (facilitadores e mediadores).

Sugerimos também que a formação de gestores, coordenadores pedagógicos e articuladores do PNME (os professores comunitários do antigo PME) há de abranger ferramentas de gestão, embutidas no desenvolvimento do Projeto Político Pedagógico da escola, para dar impulsos a processos de aceitação mútua. Instrumentos de gestão recomendados são, por exemplo, o acordo de objetivos, as sessões de avaliação formativa de professores e pessoas extraclasse, o desenvolvimento de projetos, a arbitragem (solução) de conflitos e a construção de equipes e team coaching. É necessário, a nosso ver, investir na formação (continuada) de futuros professores e gestores nas dimensões da comunicação, cooperação e capacidade de trabalhar em equipe.

\section{REFERÊNCIAS}

A GOSTINHO, M. C. E. "Administração Complexa": revendo as bases científicas da administração. RAE electron. [online], v.2, n.1, p. 0-0, 2003. Disponível em: $<$ http://www.scielo.br/pdf/raeel/v2n1/v2nla15.pdf>. Acesso em: 20 nov. 2018.

BERGMANN, K.; ROLLETT, W. Kooperation und kollegialer Konsens bzW. Zusammenhalt als Bedingungen der Innovationsbereitschaft von Lehrerkollegien an Ganztagsschulen. [Cooperação e consenso colegial respectivamente coesão como condições da disposição para inovações do corpo docente em escolas em tempo integral.] In: LANKES, E.-M.

\section{Pädagogische Profissionalität als Gegenstand empirischer Forschung.}

[Profissionalidade pedagógica como objeto da pesquisa empírica.] Münster; New York; München; Berlin: Waxmann, p. 291-301, 2008.

BRASIL. Decreto n $^{\circ} 7.083$ de 27 de janeiro de 2010. Dispõe sobre o Programa Mais Educação. Diário Oficial da União, Brasília, DF, 27 jan. 2010.

BRASIL. Lei n 9.394 de 20 de dezembro de 1996. Estabelece as diretrizese bases da educação nacional. Diário Oficial da República Federativa do Brasil, Brasília, DF, 23 dez.1996. 
BRASIL. Lei1 1.738 de 16 de julho de 2008. Regulamenta a alínea "e" do inciso III do caput do art. 60 do Ato das Disposições Constitucionais Transit órias, para instituir o piso salarial profissional nacional para os profissionais do magistério público da educação básica. Diário Oficial da República Federativa do Brasil, Brasília, DF, jul. 2008.

BRASIL. Manual Operacional de Educação Integral. Ministério da Educação/Secretaria de Educação Básica. Brasília, DF, 2014. Disponível em: < portal.mec.gov .br/index.php?.option= com_docman\&task>. A cesso em: 03 jan. 2019.

BRASIL. Ministério da Educação. Secretaria da Educação Básica. Programa Novo Mais Educação: Documento Orientador- Adesão. Brasília, 2016. Disponível em: <http://educacaointegral.mec.gov.br/images/pdf/maisEducacao/docuemn toOrientadorMaisEducacao.pdf> A cesso em: 11 dez. 2018.

BRASIL. Programa Novo Mais Educação: Caderno de orientações pedagógicas - Versão II. Ministério da Educação/Secretaria de Educação Básica. Brasília, DF, 2018. Disponível em: <http://portal.mec.gov.br/docman/junho-2018-pdf/90251-cadernoorientador-pnme/file>. A cesso em: 17 fev. 2019.

BRASIL. Portaria Normativa Interministerial $n^{\circ}-17$, de 24 de abril de 2007. Institui o Programa Mais Educação, que visa fomentar a educação integral de crianças, adolescentes e jovens, por meio do apoio a atividades sócioeducativas no contraturno escolar. Diário Oficial da República Federativa do Brasil, Brasília, DF, 26 abr. 2007.

BRASIL. Programa Mais Educação: gestão intersetorial no território. Brasília: Ministério da Educação, Secretaria de Educação Continuada, Alfabetização e Diversidade, 2009.

DIECKMANN, K.; HÖHMANN, K.; TILLMANN, K. Schulorganisation, Organisationskultur und Schulklima an ganztägigen Schulen. [pt. Organização escolar, cultura organizacional e clima escolar em escolas em tempo integral.] In: HOLTAPPELS, H.G.; KLIEME, E.; RAUSCHENBACH, TH., STECHER, L. Ganztagsschule in Deutschland: Ergebnisse der Ausgangserhebung der"Studie zur Entwicklung von Ganztagsschulen" (StEG). [pt. Escola em tempo integral na Alemanha: Resultados do levantamento diagnóstico do "Estudo para Desenvolvimento de escolas em tempo integral" (StEG)] Weinheim; München: Juventa-Verlag, p.164-185, 2007.

FUSSANGEL, K.; DIZINGER, V. BÖHM-KASPER, O.; GRÄSEL, C. Kooperation, Belastung und Beanspruchung von Lehrkräften an Halb-und Ganztagsschulen. [pt. Cooperação, estresse e tensão de professores em 
escolas em tempo parcial e em tempo integral.] e estresse

Unterrichtswissenschaft, Weinheim, v. 38, n.1, p. 51-67, 2010.

FUSSANGEL, K.; GRÄSEL, C. Kooperation von Lehrkräften. [pt. Cooperação de professores] In:BOHL, Th.; HESLPER, W.; HOLTAPPELS, H.G.; SCHELLE, C. (eds.)

Handbuch zur Schulentwicklung [pt. Manual para desenvolvimento de escolas], Bad Heikbrunn: Klinhardt, p. 258-260, 2010.

HOLTAPPELS, H. G. Neue Lernkultur - veränderte Lehrerarbeit:

Forschungsergebnisse über pädagogische Tätigkeit, Arbeitsbelastung und Arbeit szeit in Grundschulen. [pt. Nova cultura de aprendizagem - trabalho mudado do professor: resultados científicos sobre o trabalho pedagógico, a tensão e tempo de trabalho em escolas primárias.] In: CARLE, U.; BUCHEN, S. Jahrbuch für Lehrerforschung. [pt. A nuário para pesquisas sobre professores] V. 2. Weinheim; München: Juventa-Verlag, p.137-151, 1999.

HOLTAPPELS, H. G. Ziele, Konzepte, Entwicklungsprozesse. [pt. Objetivos, concepções e processos de desenvolvimento] In:HOLTAPPELS, H. G.; KLIEME, E.; RAUSCHENBACH, T.;STECHER, L. (ed.) Ganztagsschule in Deutschland: Ergebnisse der Ausgangserhebung der "Studie zur Entwicklung von Ganzt agsschulen" (StEG). Weinheim, München: Juventa Verlag. Cap. 9, p.139-163, 2007.

KAMSKI, I. Innerschulische Kooperation in der Ganztagsschule: Eine Analyse der Zusammenarbeit von zwei Berufsgruppen am Beispiel von Lehrkräften und Erzieherinnen und Erziehern. [Cooperação intraescolar na escola em tempo integral: uma análise da cooperação entre dois grupos de profissionais no exemplo de professores(as) e educadores(as)] ] Münster; New York; München; Berlin: Waxmann, 2011.

KAMSKI, I.; SCHNETZER, T. Personalentwicklung in Ganztagsschulen. [pt . Desenvolvimento de pessoal em escolas em tempo integral.] In: HÖHMANN, K.; HOLTAPPELS, H. G.; KAMSKI, I.; SCHNETZER, T. Entwicklung und Organisation von Ganztagsschulen: Anregungen, Konzepte, Praxisbeispiele. [pt. Desenvolvimento e organização de escolas em tempo integral: Sugestões, concepções e exemplos de práticas.] Dortmund, IFS-Verlag, p. 84-89, 2005.

KISSLER, L.; HEIDEMANN, F. G. Governança pública: novo modelo regulatório para as relações entre Estado, mercado e sociedade? Revista da Administração Pública - RAP, Rio de Janeiro, v. 40, n.3, p.479 - 499, 2006.

KONFERENZ DER KULTUSMINISTER (KMK). Bericht über die allgemein bildenden Schulen in Ganztagsform in den Ländern in der Bundesrepublik Deutschland: 2009 bis 2013 [Relatório sobre escolas da educação básica na reforma em prol da escola em tempo integral nos Estados da República Federativa da Alemanha: 2009 a 2013] 2.03. 2015 IV C - DST 1933-4 (20). Berlin: Sekretariat der Ständigen Konferenz der Kultusminister der Länder in der Bundesrepublik 
Deutschland, 2015. Disponível em:

<https://www.kmk.org/fileadmin/pdf/Statistik/GTS_2013_Bericht.pdf>. Acesso em: 14 dez. 2018.

MILHEIRO, R.I.A. G. L. Trabalho Colaborativo Entre Docentes - Um Estudo De Caso. 2013. 177 f. Dissertação (Mestrado em Ciências da Educação) - Escola Superior de Educação João De Deus, Lisboa, 2013.

PALMIERI, M.W. A.; BRANCO, A. U. Cooperação, competição e individualismo em uma perspectiva sócio-cultural construtivista. Psicol. Reflex. Crit. [online], v.17, n.2, p. 189-198, 2004. Disponível em:

<http://www.scielo.br/pdf/prc/v17n2/22471.pdf> Acesso em: 20 dez. 2018.

RÖBKEN, H. Bildungsmanagementin der Schule: Eine Bildungseinrichtung effektiv und nachhaltig führen. [pt. Gestão educacional na escola: gerir uma organização de ensino de forma efetiva e sustentável.] München:

Oldenbourg, 2008. (Schulmanagement-Handbuch, Bd. 125).

SCHMITZ, H.; ROLLETT, W.; SILVA, C. B. Escola em Tempo Integral na Alemanha e no Brasil: Uma Discussão dos Conceitos e de Resultados de Pesquisas Nacionais. Educação em Revista, Marília, v.18, p. 43-72, 2017.

SILVA, J. M.de C. Cooperação entre Professores: Realidade(s) e Desafios. 2002. 233 f. Dissertação (Mestrado em Psicologia Educacional) - Instituto Superior de Psicologia Aplicada, Lisboa, 2002.

Recebido em: 16 de março de 2019. Aprovado em: 01 de abril de 2019. 